\title{
Common Marine Organisms: A Novel Source of Medicinal Compounds
}

\author{
Harshita Singh ${ }^{1}$, Adyasha Parida ${ }^{1}$, Khumbar Debbarma ${ }^{1}$, Deb Prasad Ray ${ }^{2}$ and \\ Pradipta Banerjee $3^{3^{*}}$
}

\begin{abstract}
${ }^{1}$ Department of Fisheries, Centurion University of Technology and Management, Paralakhemundi, Odisha, India ${ }^{2}$ ICAR-National Institute of Natural Fibre Engineering and Technology, Kolkata, West Bengal, India

${ }^{3}$ Department of Biochemistry and Plant Physiology, Centurion University of Technology and Management, Odisha, India

"Corresponding author: pradipta.banerjee@cutm.ac.in
\end{abstract}

Received: 21-09-2019

Revised: $17-11-2020$

Accepted: 07-12-2020

\begin{abstract}
Marine environment represents innumerable and various resources for the advancement of new drugs to fight major diseases. It is an excellent ecological resource that comprises of various aquatic plants and animals from which some organisms are reported and some are still unknown, theses aquatic organisms are known to have concealed therapeutic potential and are still in trial phase. They are known for antibiotic, antiviral, anti-inflammatory, anticancer, anti-fungal, anti-obesity, Immuno-protective activities. Some of the non-commercial marine organisms are also known to have medicinal properties that are being used in pharmaceutical industries. The nutrient profile of fishes has been reported that the fishes are the sources of superior nutrients and have innumerable health benefits. Seafood eliminate the food crisis in the developing countries it fulfills the basic food requirements by providing sufficient amount of essential minerals and nutrients to the peoples. Seafood contains vast amount of omega- 3 fatty acid, which is an essential part of cell membrane they contribute in regulating hormone, blood clotting, regulate genetic function etc. and it contains n-3 PUFA such as EPA and DHA, which can treat diseases like arteriosclerotic and thrombotic. As marine environment is vast and mysterious in itself it is not yet possible for the scientists to have discovered each and every organism present, there might still be some left undiscovered so in this way we keep being benefitted by them even in the far future as the scientists are still keeping up their work of exploiting this enormous marine environment. The bioactive compounds of various marine organisms with medicinal properties and health benefits have been discussed below.
\end{abstract}

Keywords: Marine organisms, seafood, anti-inflammatory, anticancer, anti-fungal, anti-obesity, PUFA

Marine environment is a dynamic environment, which is having most valuable natural resources and provide majority of the food in the form of finfish, shellfish and seaweed. Marine water contains enormous amounts of biodiversity, which makes it as a source of huge amounts and wide varieties of bioactive compounds with great therapeutic potential (National Research Council, 1999). In recent years, many bioactive compounds have been extracted from various marine animals like tunicates, sponges, corals, and other marine organisms (Jha and Zi-rong, 2004). These bioactive molecules possess antibiotic, antiviral, anti-inflammatory, anticancer etc activities. Few marine species of medicinal uses are for example codfish, which is used to treat cardiovascular diseases (Larsen et al. 2011), Alaska Pollock, which is used to treat blood pressure, stroke, etc. (Kim and Pallela, 2012), seaweed like green alga ulva lactuca contains anti-

\footnotetext{
How to cite this article: Singh, H., Parida, A., Debbarma, K., Ray, D.P. and Banerjee, P. (2020). Common Marine Organisms: A Novel Source of Medicinal Compounds. International Journal of Bioresource Science, 7(2): 39-49.
}

Source of Support: None; Conflict of Interest: None 
inflammatory compounds, Ulva fasciata has been found to have antiviral activity.

Asian's regular diet is mostly based on seafood, which is rich in protein and is medicinally valuable therefore, the worth of marine organisms is concerned with medicinal and nutraceutical approach so that utilization of frequently available marine organisms can lead to foremost diet practices for human (Kim and Pallela, 2012). Seafood is healthy and rich in omega-3 fatty acid, which is mostly extracted from salmon and is useful in brain development. Nowadays omega- 3 fatty acid is readily available in the market as a supplement, which makes it easy for the human to consume it on daily basis. It contains good cholesterol. By incorporating marine organisms and products in our regular diet is fundamentally a step towards upgrading our mental and physical health. Seafood is currently accepted as an essential food for humans as it is abundant of high quality protein like n-3 polyunsaturated fatty acids (PUFAs), trace elements vitamins and minerals.

Functional food contributes key nutritional function and lessens the risk of life style related diseases. The derived bioactive components from seafood helps in building imbalanced dietary habits and ward off lifestyle related diseases (Hosomi et al. 2012).

\section{Biological availability of marine organisms}

Ocean contains a wide variety of living organisms having divergent physiology and capability to adapt their environment. The marine environment contribute extensive opportunities to come across new marine products which contains approximately 13,000 molecules reported out of which 3000 molecules occupy active properties. It contains around $80 \%$ of diversified plant and animal species, such genetic diversity manifest medicinal properties, which generate a promising new drug development from the biologically available marine organisms. About $25 \%$ of pharmaceutical products are obtained from plant natural products and additional $12 \%$ products are derived from biologically available microbes in the marine environment (Jha and $\mathrm{Zi}$ rong, 2004).

In general, marine natural compounds act as secondary metabolites. The marine environment occupies a wide variety of thermal range, pressure range, nutrient range and it has extensive photic and aphotic zones, this extensive variability provides new therapeutic agent for commercial use.

\section{Medicinal uses from marine organisms}

\subsection{Finfish}

Fish is an important component of human diet. Fish contains proteins and other nitrogenous compounds, lipids, minerals and vitamins and low level of carbohydrates. It is an excellent source of medicine which helps in curing various diseases as shown in the Table 1. Fish proteins contain the essential amino acids in the required proportion and thus, improve the overall protein quality of a mixed diet. The biochemical composition of moisture, protein, fat, ash are $65-80 \%, 15-20 \%$, $5-20 \%, 0.5-2 \%$ respectively. The intake of fish providen-3 polyunsaturated fatty acid (n-3 PUFA), eicosapentaenoicacid (EPA), docosahexaenoicacid (DHA) which tend to health promoting effects. Oily or fatty fish helps in preventing various health problems from mental illness to blindness.

Some of the important fish byproducts available are fish liver oil which is rich in glycogen and fat along with vitamin A and D, fish body oil contains high iodine value, fish flour contains approximately $35 \%$ which is an ideal protein supplement which helps in reducing malnutrition, anaemia etc., fish roe is a good source of vitamin B, C, D, E and Shark pancreas is rich in insulin (Fig. 1). Fish oil containing PUFA-1 is useful in treating coronary (Blondeau et al. 2015), CVD and brain function, fish meal containing vitamin $\mathrm{A}, \mathrm{B}, \mathrm{D}, \mathrm{E}, \mathrm{K}$, vitamin $\mathrm{A}$ acts as antioxidant helps in growth and development and healthy vision, vitamin $B$ helps in neurological function, energy metabolism, RBC formation, etc., vitamin $\mathrm{D}$ helps in the formation of bones and teeth, vitamin E helps in blood cell formation and immune boasting and vitamin $\mathrm{K}$ helps in blood clotting in our body.

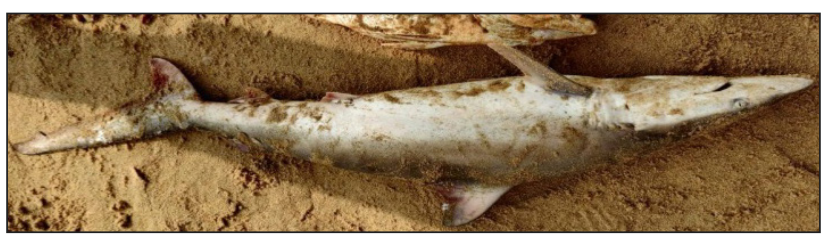

Fig. 1: Shark pancreas is rich in insulin (Photo taken in Palasa Beach, Andhra Pradesh; Photo credit: Singh, H. 2019) 
Table 1: List of marine species having potential medicinal uses (Adapted from Kim and Pallela, 2012).

\begin{tabular}{lll}
\hline Name of the Species & Scientific Name & Medicinal Uses \\
\hline Electric eel & Electrophorus electricus & Headache, acne, skin spot, wounds and pain \\
$\begin{array}{l}\text { Long snout sea horse } \\
\text { Big eye tuna }\end{array}$ & Aippocampus reidi & Asthma, epilepsy \\
& Bhunnus obesus & CVD, cancer, Alzheimer's disease \\
Cod fish & Gadus macrocephalus & CVD, skin diseases \\
Alaska Pollock & Theragra chalcogramma & Heart diseases \\
Shark & Rhinchodon typus & Cancer, psoriasis \\
Ooligan fish & Thaleichthys pacificus & Skin diseases \\
Ray & & Weakness \\
Star fish & Echinaster brasiliensis & Asthma \\
Star fish & Echinaster echinophorus & Asthma \\
Star fish & Luidia senegalensis & Asthma \\
Star fish & Mellita quinquiesperforata & Asthma \\
Star fish & Oreaster reticulatus & Asthma \\
Mussel & Pteriomorphia sp. & Hypertension \\
Abalone & Haliotis asinina & Cough and immune disorder \\
Sea urchin & Echinometra lucunter & Asthma \\
\hline
\end{tabular}

\subsubsection{Mode of action of fatty acids found in finfish}

Omega-3 fatty acids are an essential part of cell membrane and affect the function of the cell receptors in these membranes. It is highly recommended by nutritionist as it is known to be one of the major cause in reducing risk for cardiovascular diseases (Cleveland Clinic, 2019). They contribute for regulating the hormone, blood clotting, relaxation of artery wall, etc. They bind to receptors in cell that regulate genetic function. Omega-3 fats are crucial family of polyunsaturated fats. There are three main omega- 3 fatty acids i.e. Eicosapentaenoic acid (EPA), Docosahexaenoic acid (DHA) and Alpha-linolenic acid (ALA) (Clevel and Clinic, 2019). Mostly found in salmon, anchovy and tuna like fatty fish (Gammone et al. 2018 ).

Seafood contains an adequate amount of DHA, especially fatty fish and various form of $n-3$ supplements. Docosahexaenoic acid (DHA) is a bioactive omega-3 polyunsaturated fatty acid that effects membrane structure and function, cell signaling and communication channel, gene expression (Calder, 2016). PUFAs like DHA helps in improving bioactive lipid mediators formed through the cyclooxygenate and lipooxygenate pathway. These mediators are mostly recognized for their roles in inflammation, immunity and smooth muscle contraction (Freitas and Campos, 2019).
Eicosapentaenoic acid (EPA) can be used as a possible therapeutic approach to decrease cardiovascular risk. EPA is effective in protection against endothelial disorder. It is known to employ beneficial effects on a broad array of inflammatory processes. It has antioxidant property which aids in reducing oxidative stress. It is also useful in reducing levels of triglycerides (TGs) and triglyceride lipoproteins (TRLs). EPA can be known as an effective source of therapeutics because of its potential advantageous pleiotropic effects (Borow et al. 2017).

\subsection{Shellfish}

Shellfish is a major contributor in our global aquatic food supply. It consists of mostly crustaceans and mollusks (Streit, 2019). It has also been contributing to a great extent among the marine resources to provide significant medicinal prospects to human. They are low in calories and rich in protein and omega-3 fatty acid. They also contain rich amount of micronutrients along with iron, zinc, magnesium and vitamin- $B_{12}$ (Streit, 2019). Crustaceans are the major sources for many novel nutraceuticals and functional food. It has been seen that shell of shrimps and crabs are used for extraction of chitin, chitosan, chitooligosaccharide (COS) which is used in various biomedical significances. Chitin is the most important polysaccharide, whereas chitosan is an important biological applicant in 
pharmaceutical, nutraceutical and cosmeceutical industries (Venugopal and Gopakumar, 2017).

\subsubsection{Medicinal uses of shellfish}

- Shellfishes are loaded with zinc which is useful in immune boosting (Streit, 2019). By consuming shellfish regularly one can improve their $\mathrm{Zn}$ status and immune function.

- Vitamin $\mathrm{B}_{12}$ have been linked to high blood level. Therefore, consuming food rich in vitamin $\mathrm{B}_{12}$ helps in protection against heart disease. It is also useful in enhancing brain development.

- Shellfish are loaded with protein that may aid a positive notion for the supplementing of high ranked nutrition.

- Inadequate intake of crustaceans can control the collagen and other protein disorders.

- Fermented marine food products such as blue mussel sauce and oyster sauce contain bioactive peptides which play a major role as Angiotensin I converting enzyme inhibitor that indirectly suppress hypertension (Kim and Pallela, 2012).

- Dried abalones are sold in the market as herbs. It has highly valued healing powers and it is considered for treating eye disease etc.

- Drug made from abalone juice named as Paolin act as an inhibitor of penicillin-resistant strains of bacteria.

- The flat shell of the abalone iridescent present inside, is powdered which is used to improve vision.

- The juice of oyster has antiviral properties which leads to development of drugs.

- Pearls from the oyster are being powdered and used as a topical eye medicine. It has also some anti-inflammatory effects.

- The bones of the cuttle fish are used to heal rickets and acts as a healing agent for gastrointestinal (GIT) troubles. It also acts as antihemorrhagic agent (Kim and Pallela, 2012).

\subsection{Seaweed}

Seaweed is a famous intricacy and a source of crucial food hydrocolloids i.e., agar,alginates and Carrageenan (Rajapakse et al. 2011). The marine algae are considered as marine macro algae or seaweeds (Suleria, 2018). They can grow both in shallow coastal waterbodies and deep sea waters having a depth of $180 \mathrm{~m}$. The algae are categorized into three main groups and those are brown (Phaeophyceae), red (Rhodophyceae), and green algae (cholorophyceae). The marine alga contains numerous biological and biomedical activities along with extensive amount of sulfated polysaccharides. Besides, the food value has several health benefits. It contains abundant amount of health promoting molecules along with materials like dietary fiber, omega-3 fatty acids, essential amino acids and vitamin A, B, C and E (JM. Arif et al. 1970). Edible seaweeds are rich in bioactive compounds and act as a novel food helps in preventing diseases as well as having many therapeutic properties such as antiobesity, antiviral, antifungal, antibacterial, antidiabetic, antihypertensive, immunemodulatory, antihyperlipidemic, anticoagulant, antiinflammatory, antiestrogenic, thyroid stimulating, neuroprotective, anticancer, antioxidant and tissue healing properties. The intake of seaweed helps reducing the risk of calcium deficiency (Alisha et al. 2019).

Seaweeds are the natural bounty of the sea having extraordinary medicinal properties and having a wide variety of bioactive compounds as mentioned in Table 2, 3 (Khalid et al. 2018).

\subsubsection{Types of seaweeds}

Presently the algae are categorized into four domains i.e., Bacteria, Plantae, Chromista, Protozoa. All these vary in their features - morphology and sizes. According to their size algae are classified in to two groups i.e., phytoplankton (microalgae with 5000 different species) and seaweed (macro algae having 6000 different species. The three main algal divisions based on their natural pigmentation marine algae are categorized into brown, red and green algae. The colour of the phaeophyceae is due to the presence of fucoxanthin pigment, which has many physiological function and biological properties like anticancer effect. The colour of Rhodophyceae is due the presence phycoerythrin and phycocyanin pigments, which has anti-oxidative, anti-inflammatory properties. The green colour Chlorophyceae is due 
the presence of chlorophyll pigment, which helps in the production of RBC and used for detoxification (Khalid et al. 2018).

Table 2: List of bioactive compounds from different seaweed

\begin{tabular}{ll}
\hline Seaweed & Bioactive Compounds \\
\hline Undaria pinnatifida & Fucoxanthin \\
Porphyra sp. & Phycoerythrobilin \\
Phaeophyceae & Sulfated fucoidans \\
Rhodophyceae & Sulfated galactans \\
Codium fragile & Xyloarabinogalactzns \\
Codium cylindricum & Sulfated galactans \\
Sargassum thunbergii & Phlorotannins \\
Saccharina japonica & Fucoidans \\
Eiseniabicyclis & Phloroglucinol \\
Taonamaria atomaria & Stypoldion \\
Laurencia microcladia & Sesquiterpeneelatol \\
Corallina pilulifera & Ethanolic extract \\
Schizymeniadubyi & Sulfated glucuronogalactan \\
Lobophora variegate & Fucans \\
Ecklonia cava & Phlorotannin6,6'-bieckol \\
Poriphyria dentate & Catechol, rutin and hesperidin \\
\hline
\end{tabular}

Table 3: List of bioactive compounds and their biological activities

\begin{tabular}{|c|c|}
\hline Biological activities & Bioactive Compounds \\
\hline Antioxidant activity & Fucoxanthin, phcoerythrobilin \\
\hline Anticoagulant activity & Sulfated polysaccharides \\
\hline Anticancer activity & $\begin{array}{l}\text { Fucoidans, glucans, stypoldione, } \\
\text { carotene, fucoxanthin }\end{array}$ \\
\hline Anti-viral activity & $\begin{array}{l}\text { Sulfated Glucuronogalactan, } \\
\text { Sulfated galactans, carrageenan }\end{array}$ \\
\hline $\begin{array}{l}\text { Cardiovascular disease } \\
\text { protection }\end{array}$ & Carotenoids, DHA, EPA \\
\hline $\begin{array}{l}\text { Anti-inflammatory } \\
\text { activity }\end{array}$ & $\begin{array}{l}\text { Bioactive peptides, sulfated } \\
\text { polysaccharides, fucoidan, } \\
\text { terpenes }\end{array}$ \\
\hline
\end{tabular}

\subsubsection{Medicinal value of seaweeds}

(i) Antioxidant activity: Antioxidant can protect the human health against damage by ROS and diminish macromolecules such as DNA, proteins and lipids which can cause disorders like diabetes, cancer, and neurodegenerative diseases. Marine derived bioactive peptides which have antioxidant property has been regulated through radical scavenging activity, detected by electron spin resonance. Some of the marine algae having bioactive compounds such as fucoxanthin, phycoerythrobilin etc., manifest potent antioxidant activity (Khalid et al. 2018). (ii) Anti-coagulant activity: During abnormal vascular condition, the coagulation of blood prevents the blood flow in the injured vessel wall and exposure to non-endothelial surfaces at site of vascular injury occur. Coagulation factors regulate the blood coagulation. When the endogenous or exogenous anti-coagulants interfere with the coagulation factors the blood coagulation may be prolonged or ceased. It has been reported that many anti-coagulants are extracted from marine bioactive peptides which have also been isolated from marine organisms such as marine echhiuroid worm. The sulphated polysaccharides (SPs) isolated from marine brown algae are the alternate sources for formulation of novel anticoagulants. Two types of SPs have been reported which have high anticoagulant activity. Marine red algae produce sulfated galactans also known as carrageenan and brown algae produce sulfated fucoidan (Khalid et al. 2018).

(iii) Anticancer activity: It has been reported that numerous compounds isolated from the seaweeds that have been observed to reduce the progression of cancer. The bioactive compounds of seaweeds can kill carcinogenic cells by inducing apoptosis. The isolated bioactive compounds having anticancer effect process through multiple mechanisms of action, including inhibition of carcinogenic cell growth, invasion, and metastasis. Apoptosis can be initiated either by intrinsic pathway (mitochondrialmediated) or by an extrinsic pathway (death receptor-mediated).

Due to the inhibition of apoptosis in colorectal cancer cells enhances growth of tumor, promotes the progression of neoplastic and confers resistance to cytotoxic anticancer agent. Fucoidan isolated from the brown algae fucus species have the activity against both colorectal and breast cancer. The enzymatic removal of alga, eclonia cava with its polysaccharides and polyphynolics, shown antiproliferative activity against carcinogenic cell line (Moussavou et al. 2014).

(iv) Antiviral activity: Marine derived polysaccharides as well as their lower molecular weight oligosaccharide derivatives contains a range of antiviral activity. The sulfated polysaccharides (SPs) can inhibit the replication of enveloped virus, arenavirus, rhabdovirus, orthopoxvirus etc. The chemical structure, constituent sugar, degree of 
sulfation, molecular weight, and conformation are affected the antiviral activity of algal SPs. It has been seen that sulfated polysaccharides show capability in the inhibition of novel HIV virus.

Carrageenans are of three types $\lambda_{-}, \kappa-$ and t-carrageenan, each one of them has different inhibitory effects on different viruses. It is also helpful in preventing the initial infection process of human papillomavirus(HPV). Low molecular weight carrageenan and its derivatives are known to have shown inhibition against influenza virus (FM1) induced pulmonary edema in mice. Carrageenan possesses a very wide antiviral activity against both enveloped and non-enveloped viruses (Wang et al. 2012).

(v) Anti-cardiovascular activity: Cardiovascular diseases (CVD) include disorders like coronary heart disease, cerebrovascular disease, peripheral arterial disease, rheumatic heart disease, congenital heart disease, pulmonary embolism etc. Dyslipedemia is a major cardiovascular factor of coronary heart disease. Carotenoids obtained by seaweeds are known to reduce the occurance and recurrence of the cardiovascular disease via their antioxidant action on free radicals or through anti-inflammatory action onlipoxy-genase enzyme activity. Brown algae such as Alaria crassifolia, Macrocystis pyrifera contain carotenoid helpful in treating cardiovascular disease (Cardoso et al. 2015).

(vi) Anti-inflammatory activity: Oxidative stress has a major role in lung disease,gastrointestinal disorder, atherosclerosis and endothelial disorder. Gracilaria verrucosa and Gracilaria textorii are the two types of red algae species which have been reported to have anti-inflammatory properties. Gracilaria tenuistitata helps in suppressing inflammation caused by virus. A biliprotein, called C-phycocyanin was succssesful in suppressing inflammation by restraining the production of pro-inflammatory cytokines and by restraining the expression of inducible nitric oxide synthase and cyclooxygenase- 2 and it was extracted from Spirulina plantensis. Lobophora variegate a species of brown algae contain high amount of fucann that shows anti-inflammatory property (Khalid et al. 2018).

\subsection{Coral reef}

Coral reef known as jewels of the sea. It is not only a nursery to the marine organism but also has an excellence medicinal property. Corals are an important source to treat diseases likearthritis, Alzheimer's, cancer, bacterial diseases, heart disease, viral disease etc. (Poo, 2018). various corals has different kinds of bioactive compounds present in them which possesses enormous health benefits in them it is mentioned in the table below (Table 4). They have wide range of pharmaceutical properties and are used in development of novel drugs. They also have enormous potential in development of pesticides, novel commercial products, enzyme and nutritional supplements. It is used in joining of broken bones. Zidovudina (Poo, 2018), a medicine is used to treat HIV was made from the component of Caribbean sponge (Bouley, 2015). Ara-A and AZT, antiviral drugs and Ara-C, anticancer agent are the extraction of Caribbean sponges (Bruckner, 2019).

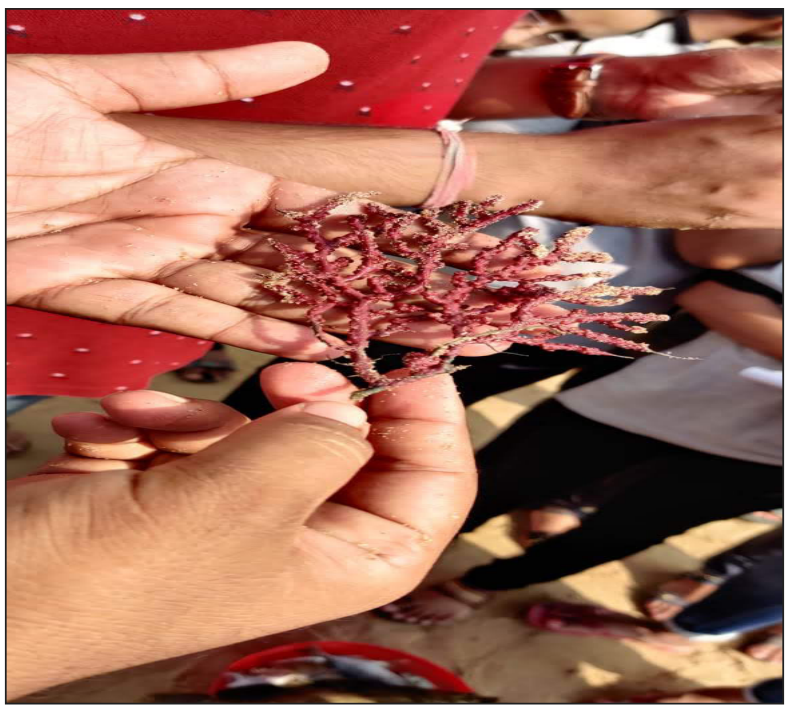

Fig. 2: Red coral reef, Palasa Beach, Andhra Pradesh, 2019 (Photo credit: Parida, A., 2019)

The species of soft coral genus Sinularia possess anti-cancer property. Steroid isolated from Sinularia crassa inhibit liver cancer as well as down grade the pro-inflammatory activity. 13-acetoxysarcocrassolide having cytotoxic property against bladder cancer cell is isolated from soft coral Sarcophyton crassocaule (Su et al. 2011). Michaolides and lobomichaolides are novel cembranolides isolated from the soft coral Lobophytum michaelae possess antitumor capability. Eunicea fusca contains three diterpenes which were known to have higher level of antiinflammatory effects (Reina et al. 2011). One of the diterpene isolated from the same species showed antimicrobial activity along with anti-inflammatory 
Table 4: List of bioactive compounds with health claims from different coral reef (Cooper et al. 2014).

\begin{tabular}{lll}
\hline Scientific Name & Bioactive Compounds & Health Claims \\
\hline Sinularia flexibilis & Flexibilin D, flexibiliquinone & Anti-inflammation \\
Sinularia gaweli & $5 \alpha, 8 \alpha$-Etidioxysterol & Cytotoxicity \\
Sinularia granosa & 9,11 -Secosterol & Anti-inflammation and Cytotoxicity \\
Sinularia crassa & Crassalone A & Cytotoxicity \\
Sinularia querciformis & II-epi-Sinulariolide, sinularin, acetate & Anti-bone loss, Anti-inflammation, anti- \\
& & neuroinflammation and antinocicettion \\
Cladiella krempfi & Kremptielins & Anti-inflammation and cytotoxicity \\
Capnella imbricata & capnellenes & anti-neuroinflammation and antinocicettion \\
Echinomuricea sp. & Echinoclrodane A. & Anti-inflammation and Cytotoxicity \\
Scleronephthya gracillimum & Sclerosteroids & Anti-inflammation and Cytotoxicity \\
Paraminabea acronocephala & Paraminabic acid & Anti-inflammation and Cytotoxicity \\
Lemnalia cervicomi tenuis & Lemnalol & Anti-inflammation and antinocicettion \\
Nephthea chabrolii & Nebrosteroids Q,R and S & Cytotoxicity \\
\hline
\end{tabular}

activity (Maehira et al. 2011). Scleractinian corals are used as a source in reducing blood pressure. 11-dehydrosinularolide, neuroprotective compound extracted from a coral to treat Parkinson's disease (Chen et al. 2012). Argonite found in Scleractinian hard coral, calcite found in soft octocorals helps in protection against, and reversing bone loss in mice placed into anartificial induced menopausal state (Banu et al. 2012).

Red coral reefs (Fig. 2) are soft corals which belongs to the phylum cnidaria, it do not produce calcium carbonate. Generally raw red coral in itself is not much with a medicinal value but after converting it into a red coral gem stone it has quite a few medicinal benefits like purifying blood and wound healing properties etc. (Galli et al. 2016).

\subsection{Sea snake}

The family hydrophiidae consists of species like sea snake. Fuanntai, which is an anticarcinogenic drug, has been extracted from sea snake which has antiblastic effects on stomach cancer, Rhinocarnoma, leukemia cells and cervical carcinoma (Zi-rong, 2004).

\subsection{Cephalopods}

\section{(i) Octopus}

Octopus is known as the chameleon of the sea, it has multiple hearts and brain, it has nutrients that can benefit reproductive health, it is a good source of iron, omega-3, selenium, copper, vitamin $B_{12^{\prime}}$ potassium, magnesium, and calcium. It is a great source of protein for people trying to lose weight as it is low in fat, it is useful in reducing triglycerides which helps in preventing risk of stroke and cardiac attack, it has an excellent anti-inflammatory property which helps in reducing chronic illness like heart disease. It contains taurine which is an amino acid that shows reduction in blood pressure and cholesterol level, taurine also has anti-viral as a well as antioxidant effects (Brennan, 2020).

\section{(ii) Squid}

Squid is a popular marine animal which is a cephalopod and comes under the phylum Mollusca. It is a good source of vitamin C, iron, and calcium; besides this it contains omega- 3 fatty acid and due to its high protein content, it has a great export value. Squid ink is a good source for decreasing several health problems and is widely utilized in both pharmaceutical as well as food industries. The squid ink has a striking blue-black colour and having a wide nutrient like antioxidant, low level of fat and calories. The squid ink consists high amount of taurine and hydroxylpyroline, mostly detected in neon flying squid, boreal clubhook and boreo pacific gonate squid (Jose et al. 1970).

\subsubsection{Medicinal Properties of Cephalopods}

Antimicrobial property is mostly seen in the ink of Indian squid (L. duvauceli), squid species like $O$. bartrami contains anti-cancer properties apart from that it contains also antioxidant properties, another 
Table 5: List of bioactive compounds from marine organisms with health benefits (Malve, 2016)

\begin{tabular}{lll}
\hline Compound Name & Marine Organisms & Disease \\
\hline Bryostatin & Bugula neritina & Anticancer/immune modulating activity \\
Ecteinascidin & Ecteinascidia turbinata & Ovarian cancer \\
Discodermolide & Discodermia & Immuno suppressive/anti-cancer \\
Halichondrin B & Lissodendoryx sp. & Blocks celldivision caused due to disruption of microtubule \\
& & structure \\
Cytarabine, ara-C & Sponge & Cancer, leukemia \\
Tetrodotoxin & Puffer fish & Chronic pain \\
Pseudopterosins (glycosides) & Pseudopterogorgia elisabethae & Anti-inflammatory/analgesic drugs \\
Ziconotide & Cone snail & Pain \\
Piltidepsin & Tunicate & Cancer \\
Plakortin & Sponge & Malaria \\
Pezizavesiculosa $\beta$-carboline & Bryozoa & Fungal infection \\
Pulicatin A & Bacteria & Immunity \\
Floridosides & Alga & Inflammation \\
Calyculin A & Sponge & Nervous system \\
Capnellene & Soft coral & Inflammation \\
\hline
\end{tabular}

species that contain antioxident property is Spendid squid (L. formosana). Squid ink helps in lowering blood pressure and is a potential anti-hypertensive. Ink from L. duvauceli and Sepiella inermis is known to have antiretroviral activity it showed strong inhibition of MMLVRT (Molony Murine Leukemia Virus Reverse Transcriptase). Squid ink increases the haematopoiesis, which helps in strengthening immune system. It also has its implementation in homeopathic and traditional medicine (Hossain et al. 2018).

\subsection{Jelly fish}

Jelly fishes are bioluminescent, some are transparent, and some produce bright colours like yellow, blue, and pink and they belong to phylum cinidaria. The body of jelly fish is mostly made up of water and they have no brain, eyes, heart, bones, and most other organ. Their body is controlled by nervous system.

\subsubsection{Medicinal Properties of jelly fish}

- The calcium binding protein of jelly fish is helpful to maintain healthy cells and also considered good for human brain.

- It contains low calories with carbohydrates which is helpful for weight loss. It is also helpful for lowering high blood pressure (McGrane et al. 2019).

- Jelly fish has been reported to possess insecticidal, anticoagulant, antihypertensive and immunostimulative effects (Lee et al. 2017).

- Rhopilema esculentum jelly fish contains active components that exhibit insecticidal activities (Liu et al. 2012).

- N. nomurai releases a collagen extract which can stimulate the production of immunoglobulin as well as cytokines without causing the allergic issues which indicate the regulatory effects on the immune system (Yu et al. 2005).

- N. nomurai is a potential food for human as it contains antioxidant property(Frazão et al. 2016). It also has a glycoprotein, called qniunucin which has the ability to inhibit degeneration of articular cartilage (Lee et al. 2017).

- The venom of Aurelia aurita has anticoagulant effects, which act through strong fibrinogrnolytic activity (Rastogi et al. 2012).

\subsection{Other marine organisms of medicinal value}

As mentioned previously, marine animals are the abundant source of diversified biologically and biomedically important material. One of the traditional and ancient medicinally important chordate is seahorse, which acts a key role as an ingredient in different therapies for variety of disorders including asthma, arteriosclerosis, thyroid disorders, skin ailments, etc. The seahorse (Syngnthus acus) is an important traditional medicine 
Table 6: List of marine organisms with health claims (Ruiz-Torres et al. 2017).

\begin{tabular}{llll}
\hline Marine Organism & Compound & Diseases & Approval Years \\
\hline Cryptothecacrypta (sponge) & Spongothymidine, spongoeuridine & Cancer & 1969 \\
Cone snail & Zinconotide & Pain & 2004 \\
Tunicate & Trabactedin & Cancer & 2007 \\
Sponge & Eribulinmesylate & Breast cancer & 2010 \\
Mollusk & Brentuximabvedotin & Lymphoma & 2011 \\
\hline
\end{tabular}

from sea, which possesses amino acid,proteins, trace elements, etc. In addition, S. acus has sexual hormones, anticancer, fatigue-resistance effects and enhances the immunity and heart muscles (Kim and Pallela, 2012). The marine bioactive peptides which are having anticoagulant properties have been isolated from marine organisms like echiuroid worm.

\section{Evolution of medicine from marine creatures}

In these past years, the marine environment has become a pharmaceutical hub, it has become a habitat to various marine organisms having wide medicinal properties. Marine plants, animals, microbes produce bioactive compounds that have potential as pharmaceutical. Most of the marine organisms such as bryozoans, mollusks, algae, ascidians and cinidarians having bioactive molecules with a great therapeutic potential, by the advancement of time based on the knowledge of biochemical, molecular structure and biochemical target the drugs has been designed.

The bioactive compound, tetrodotoxin isolated from puffer fish (Fig. 3), which is helpful curing for chronic pain.

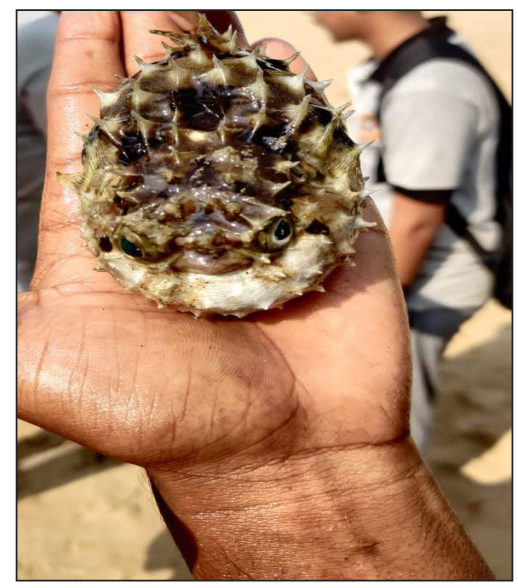

Fig. 3: Puffer fish (Photo taken in Palasa Beach, Andhra Pradesh; Photo credit: Debbarma, K., 2019)

\section{CONCLUSION}

In the past few years, marine environment has become a source which is the most utilized and trusted for drugs with therapeutic uses, bioactive compound etc. Marine organisms have excellence potential against several diseases due to the natural biomedical compounds present in them. Drugs for deadly human diseases like cancer and AIDS have been mostly extracted from several marine species. By including seafood in our daily diets can fulfill the basic health needs because it is rich in vitamins, minerals, fats and protein. It is important to promote the consumption of seafood and try to reduce the intake of high fat and high sugarfoods including fast food. By replacing the fast foods, high in sugar and fats with seafood one can maintain a healthy and guilt-free life. Due to the extensive uses of available marine organisms in medicinal as well as in their consumption leads to the exploitation of marine environment. Therefore, the sustainability should be kept in mind for our future generation.

\section{REFERENCES}

1. Banu, J., Varela, E., Guerra, J.M., Halade, G., Williams, P.J., Bahadur, A.N., Hanaoka, K., and Fernandes, G. 2012. Dietary coral calcium and zeolite protects bone in a mouse model for postmenopausal bone loss. Nutrition research (New York, N.Y.), 32(12): 965-975.

2. Blondeau, N., Lipsky, R.H., Bourourou, M., Duncan, M.W., Gorelick, P.B. and Marini, A.M. 2015. Alpha-linolenic acid: an omega-3 fatty acid with neuroprotective propertiesready for use in the stroke clinic?. BioMed Research International, pp. 519830.

3. Borow, K., Mason, R. and Vijayaraghavan, K. 2017. Eicosapentaenoic Acid as a Potential Therapeutic Approach to Reduce Cardiovascular Risk in Patients with End-Stage Renal Disease on Hemodialysis: A Review. Retrieved January 18, 2021.

4. Brennan, D. 2020. Are There Health Benefits to Eating Octopus? Pros and Cons, Nutrition Information, and More. Retrieved January 19, 2021, from https://www. webmd.com/diet/health-benefits-octopus\#1 
5. Bruckner, A. 2019. Life-Saving Products from Coral Reefs. Retrieved January 19, 2021, from https://issues. org/p_bruckner/

6. Calder, P.C. 2016. Docosahexaenoic Acid. Annals of Nutrition $\mathcal{E}$ Metabolism, 69(Suppl 1): 7-21.

7. Cardoso, S., Pereira, O., Seca, A., Pinto, D. and Silva, A. 2015. Seaweeds as Preventive Agents for Cardiovascular Diseases: From Nutrients to Functional Foods. Retrieved January 19, 2021, from https://www.mdpi.com/16603397/13/11/6838

8. Chen, W.F., Chakraborty, C., Sung, C.S., Feng, C.W., Jean, Y.H., Lin, Y.Y., Hung, H.C., Huang, T.Y., Huang, S.Y., Su, T.M., Sung, P.J., Sheu, J.H. and Wen, Z.H. 2012. Neuroprotection by marine-derived compound, 11-dehydrosinulariolide, in an in vitro Parkinson's model: a promising candidate for the treatment of Parkinson's disease. Naunyn-Schmiedeberg's archives of Pharmacology, 385(3): 265-275.

9. Cooper, E., Hirabayashi, K., Strychar, K. and Sammarco, P. 2014. Corals and Their Potential Applications to Integrative Medicine. Retrieved January 19, 2021.

10. Reina, E., Puentes, C., Rojas, J., García, J., Ramos, F.A., Castellanos, L., Aragón, M. and Ospina, L.F. 2011. Fuscoside E: A strong anti-inflammatory diterpene from Caribbean octocoral Euniceafusca. Bioorganic \& Medicinal Chemistry Letters, 21(19): 5888-5891.

11. Frazão, B. and Antunes, A. 2016. Jellyfish Bioactive Compounds: Methods for Wet-Lab Work. Marine drugs, 14(4): 75.

12. Freitas, R. and Campos, M.M. 2019. Protective Effects of Omega-3 Fatty Acids in Cancer-Related Complications. Nutrients, 11(5): 945.

13. Galli, G., Bramanti, L., Priori, C., Rossi, S., Santangelo, G., Tsounis, G. and Solidoro, C. 2016. Modelling red coral (Corallium rubrum) growth in response to temperature and nutrition. Ecological Modelling, 337: 137-148.

14. Gammone, M., Riccioni, G., Parrinello, G. and D'Orazio, N. 2018. Omega-3 Polyunsaturated Fatty Acids: Benefits and Endpoints in Sport. Nutrients, 11(1): 46.

15. Hosomi, R., Yoshida, M. and Fukunaga, K. 2012. Seafood Consumption and Components for Health. Global Journal of Health Science, 4(3).

16. Hossain, M., M.s., R. and T., H. A. 2018. Medicinal and therapeutic properties of cephalopod ink: A short review. Food Research, 3(3): 188-198.

17. Poo, D.C.T. 2018. Did you know coral reefs produce medicine? [Blog Post]. Retrieved from https://aidaamericas.org/en/blog/did-you-know-coral-reefs-producemedicine

18. Bouley, T. 2015. The (actual and scientifically derived) healing power of the sea [Blog Post]. Retrieved from https:// blogs.worldbank.org/voices/actual-and-scientificallyderived-healing-power-sea

19. Cleveland Clinic. 2019. Omega-3 Fatty Acids [Blog Post]. Retrieved from https://my.clevelandclinic.org/health/ articles/17290-omega-3-fatty-acids
20. McGrane, M.K.S. 2019. Can You Eat Jellyfish?Healthline. https://www.healthline.com/nutrition/can-you-eatjellyfish\#benefits

21. Streit, L. 2019. What Is Shellfish? Everything You Need to Know [Blog Post]. Retrieved from https://www.healthline. com/nutrition/shellfish

22. National Research Council (U. S.) 1999. From Monsoons to Microbes: Understanding the Ocean's Role in Human Health. Washington, DC: The National Academies Press. https://doi.org/10.17226/6368.

23. Alisha, Dubey, P.R. and Haider, A. 2019. Seaweed: Nutritional and health benefits. The Pharma Innovation Journal, 8(8): 80-83.

24. Jha, R. and Zi-rong, X. 2004. Biomedical Compounds from Marine organisms. Marine Drugs, 2(3): 123-146.

25. JM. Arif, A., P. MacArtain, C., Cerna, M., L. Misurcova, S., M. Tabarsa, M., N. Rajapakse, S., . . TH. Corbett, F. 1970. Marine algal natural products with anti-oxidative, anti-inflammatory, and anti-cancer properties. Retrieved January 19, 2021, from https://cancerci.biomedcentral. com/articles/10.1186/1475-2867-13-55

26. Jose, J., K, K., and B, D. 1970. Squid ink and its pharmacological activities. Retrieved January 17, 2021, from https://doi.org/10.30574/gscbps.2018.2.3.0013

27. Khalid, S., Abbas, M., Saeed, F., Bader-Ul-Ain, H., and Suleria, H. 2018. Therapeutic Potential of Seaweed Bioactive Compounds. Retrieved January 14, 2021, from https://www.intechopen.com/books/seaweedbiomaterials/therapeutic-potential-of-seaweed-bioactivecompounds

28. Kim, S. and Pallela, R. 2012. Medicinal Foods from Marine Animals. Marine Medicinal Foods - Implications and Applications - Animals and Microbes Advances in Food and Nutrition Research, pp. 1-9.

29. Larsen, R., Eilertsen, K. and Elvevoll, E.O. 2011. Health benefits of marine foods and ingredients. Biotechnology Advances, 29(5): 508-518.

30. Lee, H., Bae, S., Kim, M., Pyo, M., Kim, M., Yang, S., . . . Kim, E. 2017. Anticancer Effect of Nemopilemanomurai Jellyfish Venom on HepG2 Cells and a TumorXenograft Animal Model. Retrieved January 19, 2021, from https:// dx.doi.org/10.1155/2017/2752716

31. Liu, X., Zhang, M., Zhang, C. and Liu, C. 2012. Angiotensin converting enzyme (ACE) inhibitory, antihypertensive and antihyperlipidaemic activities of protein hydrolysates from Rhopilemaesculentum. Food Chemistry, 134(4): 2134-2140.

32. Maehira, F., Motomura, K., Ishimine, N., Miyagi, I., Eguchi, Y. and Teruya, S. 2011. Soluble silica and coral sand suppress high blood pressure and improve the related aortic gene expressions in spontaneously hypertensive rats. Nutrition research (New York, N.Y.), 31(2): 147-156.

33. Malve, H. 2016. Exploring the ocean for new drug developments: Marine pharmacology. Journal of Pharmacy and Bioallied Sciences, 8(2): 83. 
34. Moussavou, G., Kwak, D., Obiang-Obonou, B., Maranguy, C., Dinzouna-Boutamba, S., Lee, D. and Choo, Y. 2014. Anticancer Effects of Different Seaweeds on Human Colon and Breast Cancers. Marine Drugs, 12(9): 4898-4911.

35. Rajapakse, N. and Kim, S.K. 2011. Nutritional and digestive health benefits of seaweed. Advances in food and Nutrition Research, 64: 17-28.

36. Rastogi, A., Biswas, S., Sarkar, A. and Chakrabarty, D. 2012. Anticoagulant activity of Moon jellyfish (Aurelia aurita) tentacle extract. Toxicon: official journal of the International Society on Toxinology, 60(5): 719-723.

37. Ruiz-Torres, V., Encinar, J., Herranz-López, M., PérezSánchez, A., Galiano, V., Barrajón-Catalán, E. and Micol, V. 2017. An Updated Review on Marine Anticancer Compounds: The Use of Virtual Screening for the Discovery of Small-Molecule Cancer Drugs. Retrieved January 19, 2021, from https://www.mdpi.com/1420$3049 / 22 / 7 / 1037$
38. Su, C.C., Su, J.H., Lin, J.J., Chen, C.C., Hwang, W.I., Huang, H.H. and Wu, Y.J. 2011. An investigation into the cytotoxic effects of 13-acetoxysarcocrassolide from the soft coral Sarcophytoncrassocaule on bladder cancer cells. Marine Drugs, 9(12): 2622-2642.

39. Venugopal, V. and Gopakumar, K. 2017. Shellfish: Nutritive Value, Health Benefits, and Consumer Safety. Comprehensive Reviews in Food Science and Food Safety, 16(6): 1219-1242.

40. Wang, W., Wang, S. and Guan, H. 2012. The Antiviral Activities and Mechanisms of Marine Polysaccharides: An Overview. Marine Drugs, 10(12): 2795-2816.

41. Yu, H., Liu, X., Dong, X., Li, C., Xing, R., Liu, S. and Li, P. 2005. Insecticidal activity of proteinous venom from tentacle of jellyfish Rhopilema esculentum Kishinouye. Bioorganic $\mathcal{E}$ Medicinal Chemistry Letters, 15(22): 4949-4952. 
